\title{
Determinants of Skeletal Muscle Hypertrophy and the Attenuated Hypertrophic Response at Old Age
}

\section{Hans Degens ${ }^{1,2^{*}}$}

${ }^{1}$ Institute for Biomedical Research into Human Movement and Health; Manchester Metropolitan University; United Kingdom

${ }^{2}$ Division Space Physiology, Institute of Aerospace Medicine, German Aerospace Center, Cologne, Germany

\begin{abstract}
In 2012 we will again see the impressive achievements of many athletes during the London Olympic Games. In particular for weightlifters success is dependent on the power- and force-generating capacity of their muscles, which in turn are strongly determined by muscle mass. Many athletes and bodybuilders therefore train intensively to develop as much muscle hypertrophy as possible. Unlimited hypertrophy, however, is impossible. Limitations may be imposed by the peak forces that the tendons, bones and joints can cope with, but also by factors within the muscles themselves. For instance, an increase in pennation angle, which accompanies hypertrophy, beyond $45^{\circ}$ would result in a reduction in muscle strength even if muscle mass continuous to increase. There also is a trade-off between metabolism and diffusion, where highly oxidative fibers require shorter diffusion distances, and hence smaller fibers, for adequate oxygen supply to the mitochondria, than glycolytic fibers. A similar situation applies to the myonuclei where transcripts are distributed over the cell mainly by diffusion and unbridled hypertrophy would, at least in theory, cause serious problems with fiber maintenance. Despite these limiting factors muscles in bodybuilders can be as much as $74 \%$ larger than in the normal population. Elderly people have a lower muscle mass that may cause problems with daily life activities and an increase in muscle strength would improve their quality of life. There are indications, however, that the maximal attainable hypertrophy is significantly reduced in the elderly. Here it is suggested that while individual fibers in the elderly may hypertrophy to a similar extent as their younger counterparts, the age-related loss of muscle fibers is an additional limiting factor of the whole muscle hypertrophy at old age.
\end{abstract}

Keywords: Myonuclear domain; Microcirculation; Specific tension; Anatomy; Diffusion

\section{Introduction}

This year (2012) will see the Olympic Games in London, where we will again witness the remarkable abilities of the human body. These achievements do not come easily but are the culmination of years of training and sacrifices by the participating athletes. Intense training programs make use of the ability of many body systems to adapt to altered functional demands, where in particular skeletal muscle tissue has a remarkable plasticity. In general terms, endurance training induces an increase in the oxidative capacity that enables the muscle to generate adenosine triphosphate (ATP, the energy currency in the cell) via aerobic metabolism and gives the muscle the ability to sustain submaximal workloads for a prolonged time. Power athletes, such as weightlifters, do not so much require a large endurance as an exceptional power and force generating capacity. To realize this, a substantial part of their training program exists of resistance exercise where the load of a muscle is regularly increased during the training program. In response to the increased load the muscle enlarges, or hypertrophies, and concomitantly its force and power generating capacity increase. As power is largely determined by muscle mass the weightlifter seeks to attain as much hypertrophy as possible for the appropriate muscles. But is there a limit to the degree of hypertrophy? And if so, what determines this limit of hypertrophy? These are some of the questions this review seeks to address.

Weightlifters are one end of the spectrum, but at the other end of the spectrum we have the elderly and many people with chronic disorders who may suffer from muscle atrophy and weakness. The weakness may become so severe that even an everyday task as rising from a chair becomes a major challenge. Muscle strengthening exercise is therefore regularly applied to improve the quality of life in these situations. But again, is there a limit to the gains that can be achieved, and is the maximal achievable hypertrophy maybe less or reached at a slower rate at old age? And if indeed the degree and/or rate of hypertrophy are less, what is then the cause of this attenuated hypertrophic response? These questions are also addressed.

\section{Skeletal Muscle Adaptations during Hypertrophy}

Hypertrophy and hyperplasia of muscle fibers

In humans skeletal muscle hypertrophy can be induced by resistance exercise. Increases of more than $5 \%$ in muscle volume or cross-sectional area after as little as 9-12 weeks of resistance training are no exception [1-7], where it seems that the largest and fastest development of hypertrophy is attained when eccentric contractions are included in the exercise program $[3,8]$. Bodybuilders are off course the prime example of people with enormous muscles; their muscles can be $76 \%$ larger than that of the normal population [9]. This exceptionally large muscle size may not only be attributable to fiber hypertrophy, but also to an increase in the number of fibers, or hyperplasia [10,11]. In fact, in one study the large muscle size of the bodybuilders was almost entirely attributable to a larger number of fibers, as the size of the fibers did not differ between the body builders and a control group [10]. This observation remains controversial, however, as the similar estimated fiber number in the $76 \%$ larger $m$. biceps brachii of elite bodybuilders and controls argues against fiber hyperplasia as a significant contributor to muscle hypertrophy [9].

In animals hypertrophy can also be induced by resistance exercise but a much larger response can be realized by overloading a muscle by

${ }^{*}$ Corresponding author: Dr. Hans Degens, Institute for Biomedical Research into Human Movement and Health, Manchester Metropolitan University, John Dalton Building, Chester Street, Manchester M1 5GD, United Kingdom, Tel +441612475686; Fax: +441612475751; E-mail: h.degens@mmu.ac.uk

Received January 16, 2012; Accepted February 23, 2012; Published February 27, 2012

Citation: Degens H (2012) Determinants of Skeletal Muscle Hypertrophy and the Attenuated Hypertrophic Response at Old Age. J Sport Medic Doping Studie S1:003. doi:10.4172/2161-0673.S1-003

Copyright: ( $) 2012$ Degens H. This is an open-access article distributed under the terms of the Creative Commons Attribution License, which permits unrestricted use, distribution, and reproduction in any medium, provided the original author and source are credited. 
(functional) elimination of synergist muscles (Table 1). For instance, the size of the muscle in mice, rats and cats may almost double after functional elimination of synergist muscles [12-18]. One might thus expect that if hyperplasia plays a role in muscle hypertrophy it should become particularly evident in these animal models. However, fiber counts after nitric acid digestion of the muscle showed that also in this case there is little if any hyperplasia [19]. If hyperplasia occurs it requires the recruitment of satellite cells and the same degree of compensatory hypertrophy in satellite cell-depleted and normal mice [16] provides further evidence that hyperplasia, if at all occurring, plays no significant role in muscle hypertrophy in mammals. It is only in avian muscle that stretch-overload induced hypertrophy is unequivocally accompanied with hyperplasia [20]. Indeed, the general consensus is that skeletal muscle hypertrophy is a consequence of an increase in the size of the individual fibers, while fiber hyperplasia plays no significant role, if at all, in human and mammalian muscle hypertrophy [6-8].

\section{Changes in muscle architecture}

The increase in the size of the muscle fibers poses somewhat of a problem as the length of the muscle-tendon complex, and hence the length of the aponeuroses to which the fibers can attach, are set by the anatomy and unalterable. Yet, the hypertrophied fibers need to attach to the aponeuroses. To overcome this problem the pennation angle of the fibers in a pennate muscle will increase [2,3] so that despite their increase in size they each individually leave a smaller 'footprint'.

\section{Changes in fiber type composition and metabolic profile}

During the development of skeletal muscle hypertrophy in response to resistance exercise in humans there is also an increase in the proportion of type IIA at the expense of type IIX fibers and myosin
$[8,21]$, similar to the increase in areal fraction of type I and IIA at the expense of IIB fibers in the overloaded rat plantaris muscle [18,22]. Such a transition is not limited to the myosin heavy chain profile as a fast-to-slow transition also occurs in the isoform expression of the sarcoplasmic reticulum $\mathrm{Ca}^{2+}$-ATPase in overloaded rat plantaris muscle [15]. The activities of metabolic enzymes remain largely unaltered after resistance exercise in human [23] or overloaded rat [14,22] muscle, but reductions in the citrate synthase activity and glycolytic capacity have been reported $[24,25]$. The minimal alteration in the activities of individual metabolic enzymes is reflected by an unaltered oxidative capacity of the hypertrophied muscle [26]. It should be noted, however, that though the mass-specific metabolic profile of the hypertrophied muscle is largely unaltered, the implication is that the total metabolic capacity of the muscle is increased. In other words, the metabolic capacity increases in proportion to the increase in muscle mass. As a consequence the maximal oxygen consumption per muscle (fiber) is increased and hence the total amount of oxygen delivered to the muscle during maximal exercise has to be increased. This is realized by an increase in maximal blood flow through the muscle that also is proportional to the increase in muscle mass, as reflected by a maintained maximal mass-specific blood flow [12,27]. Ultimately, the oxygen has to diffuse from the capillaries to the mitochondria and also here we see that the capillary density is maintained or slightly reduced consequent to an increase in the number of capillaries per fiber $[27,28]$. This increase in capillary number is not only almost in proportion to the increase in muscle mass, but also follows a similar time course as the hypertrophy [29].

\section{The impact of hypertrophy on skeletal muscle function}

It is to be expected that an increase in muscle size is accompanied by a proportional increase in muscle force and power generating capacity.

\begin{tabular}{|c|c|c|c|c|c|}
\hline Reference & Species & Model & Duration & Muscle & Hypertrophy \\
\hline 15 & $\begin{array}{l}\text { Rat, } q \\
13 \text { weeks }\end{array}$ & Bilateral removal gastrocnemius and soleus & 5 weeks & Plantaris & $80 \%$ \\
\hline 17 & $\begin{array}{l}\text { Rat, } \stackrel{+}{ } \\
150-170 \mathrm{~g}\end{array}$ & Bilateral removal gastrocnemius and soleus & $12-14$ weeks & Plantaris & $97 \%$ \\
\hline 56 & $\begin{array}{l}\text { Rat, } \stackrel{+}{ } \\
170-180 \mathrm{~g}\end{array}$ & Bilateral removal gastrocnemius and soleus & $\begin{array}{l}56 \text { days } \\
\text { Hypobaric hypoxia }(5,500 \mathrm{~m})\end{array}$ & Plantaris & $105 \%$ \\
\hline 18 & $\begin{array}{l}\text { Rat, } \stackrel{+}{ } \\
250-275 \mathrm{~g}\end{array}$ & Bilateral removal gastrocnemius and soleus & 30 days & Plantaris & $60 \%{ }^{*}$ \\
\hline 12 & Rat, $\hat{\sigma}$ & Bilateral removal gastrocnemius & 4 weeks & $\begin{array}{l}\text { Plantaris } \\
\text { Soleus }\end{array}$ & $\begin{array}{l}95 \% \\
40 \%\end{array}$ \\
\hline 72 & $\begin{array}{l}\text { Rat, } \hat{\sigma} \\
8.5 \text { months } \\
38.5 \text { months }\end{array}$ & Bilateral removal gastrocnemius & 8 weeks & Plantaris & $\begin{array}{l}53 \% \\
\text { NS }\end{array}$ \\
\hline 24 & $\begin{array}{l}\text { Rat, } \stackrel{+}{ } \\
150-170 \mathrm{~g}\end{array}$ & Unilateral removal gastrocnemius and soleus & 8 weeks & Plantaris & $28 \%{ }^{*}$ \\
\hline 14 & Rat, $\widehat{\partial}, q$ & Unilateral removal gastrocnemius & $30-100$ days & Plantaris & $84 \%{ }^{*}$ \\
\hline 29 & $\begin{array}{l}\text { Rat, ô } \\
232 \mathrm{~g}\end{array}$ & Unilateral removal gastrocnemius & 30 days & Plantaris & $80 \%{ }^{*}$ \\
\hline 22 & $\begin{array}{l}\text { Rat, }{ }^{+} \\
5,13,25 \text { months }\end{array}$ & Unilateral denervation gastrocnemius and soleus & 6 weeks & Plantaris & $30 \% *$ \\
\hline 37 & $\begin{array}{l}\text { Rat, } q \\
46 \text { days }\end{array}$ & Unilateral denervation gastrocnemius and soleus & 7 weeks & Plantaris & $43 \%{ }^{*}$ \\
\hline 94 & $\begin{array}{l}\text { Rat, }+ \\
\text { 6-8weeks }\end{array}$ & Unilateral removal tibialis anterior & 14-61 days & Extensor digitorum longus & $28 \%{ }^{*}$ \\
\hline 27 & $\begin{array}{l}\text { Rat, } \hat{\partial}, \\
175-260 \mathrm{~g}\end{array}$ & Unilateral removal tibialis anterior & $\begin{array}{l}2 \text { weeks } \\
8 \text { weeks }\end{array}$ & Extensor digitorum longus & $\begin{array}{l}19 \%^{*} \\
52 \%^{*}\end{array}$ \\
\hline 16 & $\begin{array}{l}\text { Mouse, } \text { + } \\
4 \text { months }\end{array}$ & Bilateral removal gastrocnemius and soleus & 2 weeks & Plantaris & $100 \%$ \\
\hline 13 & $\begin{array}{l}\text { Cat, } q \\
3.2-3.5 \mathrm{~kg}\end{array}$ & Bilateral removal gastrocnemius and soleus & 12 weeks & Plantaris & $136 \%$ \\
\hline
\end{tabular}

*: contralateral muscle served as control

Table 1: The degree of skeletal muscle hypertrophy in several animal models. 
One might argue that due to a concomitant increase in pennation angle the actual increase in force and power generating capacity maybe somewhat less than expected, but certainly not more than proportional to the increase in muscle size. It may thus come as a surprise that at least in humans the increase in force generating capacity significantly exceeds the increase in muscle mass, resulting in an increased specific tension, or force per muscle (physiological) cross-sectional area after resistance exercise $[1,2,6,30]$. While this might be due to a rise in specific tension of individual fibers, as seen in bodybuilders and after long term resistance training [11,31], such an increase has not been seen after shorter periods of resistance training [21,32]. It has been speculated that at least part of the increase in specific tension after (short-term) resistance training may be due to enhanced lateral force transmission $[5,21]$. Lateral force transmission does in fact occur [33] and it has been suggested that increased lateral connections between the fibers, via the connective tissue matrix, and the tendon could result in an enhanced force generation for a given amount of contractile material at the expense of a reduction in shortening velocity, thus not changing the power generating capacity [5]. The increase in specific tension and unchanged power generating capacity of hypertrophied human muscle [21] does appear to support this hypothesis. The proportion of noncontractile tissue does, however, not change in response to resistance exercise $[4,7]$ and even in bodybuilders it is similar to that in untrained controls [9]. Even so, an enhanced lateral force transmission might occur if the number of fibers that do not span the entire distance between the aponeuroses [34] increases, whereby in-series fibers functionally act as parallel fibers and/or if potential slippage of fibers is reduced by increased lateral connections between the fibers and surrounding connective tissue. Costameric proteins, like paxilin and focal adhesion kinase (FAK), are part of these connections and have indeed been shown to increase at least transiently, in overloaded rat and avian skeletal muscle [35].

As discussed above, the degree of hypertrophy in animal models can be much higher than that observed in humans and if lateral force transmission does occur one might expect that it would be more pronounced in these models. Yet, in contrast to humans the specific tension in the hypertrophied rat plantaris muscle shows no change $[36,37]$ or is even decreased [17], suggesting that in these models there is no, or little, enhanced lateral force transmission. While in animals an individual muscle can be maximally activated via the nerve, in humans isolated muscle stimulation is practically (admittedly direct nerve stimulation can be applied but is rather painful) impossible and voluntary contractions are often associated with the recruitment of agonists or stabilizing muscles which would obscure the traininginduced changes in the muscle of interest. It thus remains to be seen whether we do miss something when measuring specific tension in human hypertrophied muscle, or whether in contrast to animals, in humans the increased force generating capacity after resistance training is due to both increases in muscle size and enhanced lateral force transmission.

\section{Limits of Hypertrophy}

Common sense suggests that infinite hypertrophy is impossible. In fact, the absence of any further increase in muscle size in bodybuilders after an additional 24-week heavy resistance training program lends support to this notion, at least in humans [38]. But what does limit the degree of hypertrophy that can be attained? The next section of this review will discuss some factors that may prevent the development of unrestricted hypertrophy.

\section{Muscle architecture}

An excessive muscle size may physically limit the range of motion, as one can readily understand when looking at an exceptionally large biceps muscle from a bodybuilder. This maybe illustrated by a limitation of the range of motion when you place your hand on your biceps. Although potentially inconvenient, this does not in itself limit the degree of attainable hypertrophy.

It is clear, however, that unbridled hypertrophy is impossible. One limitation is the amount of contractile material that can be packed on the aponeuroses. The densest packing of contractile material can be achieved by orienting the fascicles perpendicular to the aponeurosis (or $90^{\circ}$ pennation), but any increase in pennation angle beyond $45^{\circ}$ will result in a reduction in the force and power generating capacity of the muscle even when muscle mass increases. Functionally relevant hypertrophy is thus limited by muscle architecture when the pennation angle (during contraction) exceeds $45^{\circ}$. However, angles of up to $53^{\circ}$ during submaximal isometric contractions in the $m$. triceps brachii from body builders have been reported [39].

Even in parallel-fibered muscles an increase in muscle mass is limited by the available space on the aponeurosis as hypertrophy of the deep fibers in the muscle will push overlying fibers up and by necessity cause them to curve, effectively creating a pennation angle, in order to stay attached to the aponeurosis and tendon. An increased curvature of the fascicles has indeed been shown in muscle from bodybuilders [39]. At some stage, one might conceive that contraction of the overlying fibers causes so high compressive forces on the underlying fibers that it hampers their contraction as they cannot bulge during shortening.

\section{Tendons, entheses and joints}

Larger muscles are able to generate larger forces. The muscle forces are transferred via the tendon and bony attachment (enthesis) to the joints and bones and one potential constraint of hypertrophy could thus be a limit to the forces that those structures can cope with.

Tendons are the first structure in the path of muscle force transfer to the joint. It appears that tendons are no static structure but do become stiffer in response to resistance exercise [6,40-42] and thereby probably reduce the chance of tendon injury. The increased stiffness of the tendon after resistance exercise is primarily a result of altered properties of the tendon material [40-42], but also some (regional) tendon hypertrophy may accompany muscle hypertrophy [42,43] Even in the light of such adaptations there are many tendon injuries in athletes [44] and since with tendon rupture the hypertrophic stimulus disappears it is conceivable that the tensile strength of the tendon puts some limit on the hypertrophy that can be attained. However, tendons have a significant safety factor and most tendon injuries are a consequence of 'wrong' movements rather than an excessive muscle force.

The size of the enthesis, the site of attachment of the tendon to the bone $[43,45]$, is limited by the tendon-bone interface. While tendons are able to adapt their material properties and size during muscle hypertrophy, the size and complexity of the enthesis seems to remain unaltered during muscle hypertrophy as shown in sheep [43]. The fixed size and complexity of the enthesis thus places a limit on the forces that this structure can be subjected to without incurring damage and thus may restrict the maximally attainable hypertrophy. However, the accumulation of micro-tears during repetitive overload that underlies tendinopathies and enthesopathies [45] are probably more important in limiting hypertrophy, and yet loaded repetitions are required to induce muscle hypertrophy.

While during childhood the bones and joints do appear to respond to changes in muscle strength, this is much less, if at all, the case in 
adulthood [46]. Joint size thus seems to be set at the end of puberty and it has been suggested that peak joint forces should not exceed the peak forces that the joints were adapted to during puberty to prevent failure [46]. A fixed joint size would then potentially put a limit to the maximal attainable muscle force generating capacity or hypertrophy.

\section{Neural limitations}

Motor control would ensure that the forces on the joints derived from muscle contraction will not exceed the peak forces the joint was originally adapted to [46]. The Golgi tendon organ may act as such a negative feedback controller. When the tension rises the deep tendon reflex is activated, effectively inhibiting the contraction of the muscle, and hence the hypertrophic stimulus. To perform such a function adequately also during resistance exercise or overload the responsiveness of this organ to stretch must remain stable, which has indeed been observed [47]. If this feedback loop does indeed limit the development of hypertrophy one might expect that blunting the sensitivity of the Golgi tendon organ would enhance, and increase the rate of, hypertrophy.

\section{Diffusional limitations of hypertrophy}

Capillaries and aerobic metabolism: Contractile activity and aerobic metabolism require high fluxes of oxygen, ATP, ADP and Pi within the myofiber. To regenerate ATP aerobically the mitochondria need oxygen that diffuses from the capillaries, which also serve to remove metabolites and heat. There might therefore be a trade-off between the size of a fiber and aerobic metabolism determined by diffusion limitations [48]. Indeed, an inverse relationship between the size of a fiber and its maximal oxygen uptake has been observed [49]. It should be noted, however, that the perimeter increases in direct proportion to the radius (fibers are near-circular), while the fiber crosssectional area increases in proportion to the square of the radius. As a consequence the perimeter : cross-sectional area ratio decreases with increasing fiber size. This is important as a considerable amount of ATP is used by the $\mathrm{Na}^{+} / \mathrm{K}^{+}$-pump to restore the membrane potential after each contraction, and with an increase in fiber size a lower proportion of the ATP requirement will go to the restoration of the membrane potential. Indeed, it was found in the lobster that the cost of $\mathrm{Na}^{+} / \mathrm{K}^{+}$ ATPase function was twice as large in muscles with small fibers, with a 2-fold higher surface to volume ratio, than that in muscles with large fibers [50]. Based on these considerations Johnston et al developed the hypothesis of 'optimal fiber size' which suggests that in larger fibers there is a trade-off between 'diffusion constraints' and 'metabolic cost savings' associated with a smaller surface to volume ratio [51]. In support of this hypothesis is the higher abundance of large-sized fibers in the Atlantic cod (Gadus morhua L.) with hemoglobin with a high oxygen affinity (at the given temperature) in comparison with those with hemoglobin with a lower oxygen affinity [51]. The high affinity of hemoglobin alleviates some of the diffusion constraints of oxygen in the muscle and allows larger fibers and hence a reduction in the cost of maintaining ionic homeostasis by reducing the surface to volume ratio by having larger fibers [51].

During hypertrophy the growing fibers will push the existing capillaries apart and thereby increase the average and maximal diffusion distances from the capillaries to the mitochondria (Figure 1 left panel). To overcome this problem capillary neoformation takes place $[27,28,52,53]$ with a time course similar to the growth in muscle fiber size [29]. The capillaries may also become more tortuous in overloaded muscles [54] thereby increasing the capillary - fiber perimeter contact area. These adaptations ensure that the increase in the average diffusion distance from the capillaries to the mitochondria is blunted (Figure 1 right panel), but not entirely prevented, as reflected by a lower capillary density in hypertrophied than control muscles [28,29]. Even if the capillary density stays the same, the obligatory location of capillaries at the periphery of the fibers will result in increased diffusion distances from the capillaries to mitochondria in the interior of the fiber and thus, all else staying the same, restrict fiber hypertrophy. Such a situation would be aggravated during hypoxia and it is therefore no surprise that hypertrophy in human muscle after resistance exercise in hypobaric hypoxia is less than that in normoxia [55]. Yet, in plantaris muscles from rat exposed to hypobaric hypoxia (equivalent to that at an altitude of 5,500 m) a staggering doubling of muscle size occurred after 56 days of overload [56]. One adaptation that would prevent the increase in maximal diffusion distances from the capillary to the mitochondria is a change to a more flattened shape of the fiber as seen in the Anchovy [57], but no such adaptation has been reported in hypertrophied mammalian muscle.

Facilitated diffusion of oxygen may overcome or attenuate potential problems of oxygen diffusion in the larger fibers. In fish, increased intramyofiber lipid facilitates oxygen diffusion and does indeed help to increase intracellular oxygen tension $\left(\mathrm{PO}_{2}\right)$ in eels even when fiber radius and $\mathrm{VO}_{2 \max }$ are higher as a consequence of higher activity levels [58]. It is unknown, however, whether such an adaptation also occurs in mammalian hypertrophied muscle, but it is known that the myoglobin concentration, which also facilitates oxygen diffusion [59], does remain unaltered in hypertrophied muscles [60]. There is thus little, if any, evidence for enhanced facilitated oxygen diffusion in hypertrophied muscles to compensate for the increased diffusion distances from the capillary to the mitochondria.

Another way to reduce the diffusion distances from the capillaries to the mitochondria is to move the mitochondria to the periphery of the fiber [61]. While such a redistribution of mitochondria does decrease the diffusion distance of oxygen it simultaneously increases the diffusion distances for the adenonucleotides, which then instead may limit muscle fiber size, particularly since radial diffusion of adenonucleotides is restricted by the myofilament lattice [62]. Yet, the mitochondria are still normally distributed within the fibers as are the associations between the metabolic pathways and ATP utilization in $136 \%$ hypertrophied cat plantaris muscle [13]. Although the total oxidative capacity of the muscle fibers was unaltered in this case, in mass specific terms it was, in contrast to the less hypertrophied rat plantaris

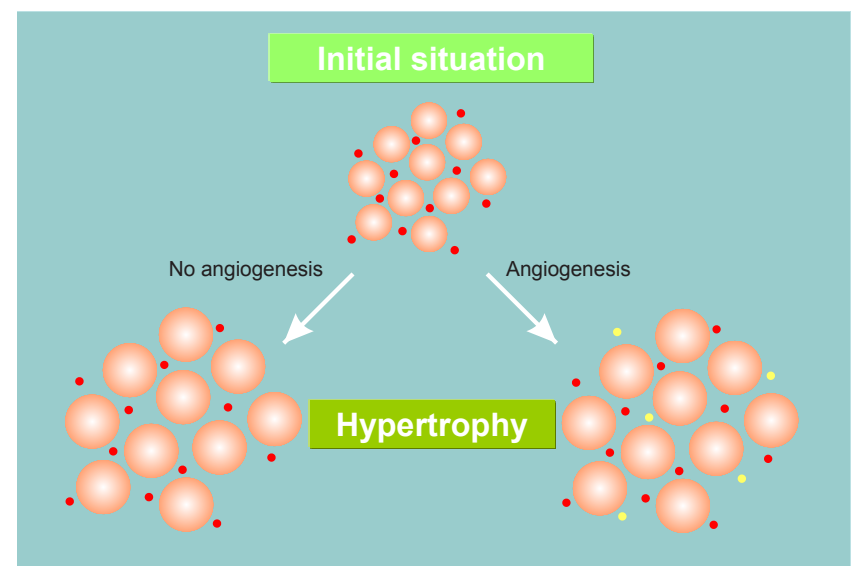

Figure 1: During hypertrophy of muscle fibers the capillaries are pushed apart, resulting in t diffusion distances that could hamper muscle oxygenation. Angiogenesis, the formation of new capillaries, indicated in the left panel as yellow dots, maintain the average diffusion distances. 
muscles, reduced [13], suggesting that this massive hypertrophy is close to what is maximally attainable.

Although the $136 \%$ hypertrophy in cat muscle [13] seems to be close to the maximum attainable hypertrophy they are still very much smaller than the $600-\mu \mathrm{m}$ diameter fibers in the blue crab Callinectes sapidus [61]. To realize the exceptional maturational growth of fibers from less than $80 \mu \mathrm{m}$ in diameter to fibers with diameters as larger as $600 \mu \mathrm{m}$ in the blue crab the fibers, though acting as a functional unit, become metabolically subdivided where each subdivision is wellperfused with hemolymph and maintains a constant diameter [61]. This effectively overcomes the metabolic and diffusional constraints of fiber growth. In fact, without subdivisions the aerobic fibers would not be able to sustain the observed aerobic fluxes [61]. This thus shows that indeed the degree of maximally attainable hypertrophy can be limited by metabolic and diffusional constraints.

Myonuclei: The myonucleus provides a template for the production of all the ribonucleic acids (RNA) in the cell. The volume of cytoplasm supplied by a nucleus is called the myonuclear domain. It has been suggested that the myonuclear domain size is limited by the halflife of RNA and the rate of diffusion of the RNA [63,64]. In a recent review we already discussed the relationship between myonuclear number and muscle fiber hypertrophy [64] and therefore it will not be discussed extensively here. In essence, similar to capillaries, the nuclei in mammalian muscle fibers are almost exclusively located at the periphery of a fiber and hence this may cause problems with the diffusion of RNA to the center of the fiber. Since radial diffusion of RNA is severely restricted by the filament lattice and less so in the axial direction of muscle fibers [63] it might in fact be more important to maintain the nuclear number per perimeter ratio during hypertrophy [64]. Given these considerations, one would expect that also during exercise or overload-induced hypertrophy, fiber growth has to be accompanied by addition of new myonuclei and yet, significant hypertrophy is possible without the addition of myonuclei $[16,64-66]$. But also here, like metabolic and diffusion constraints above, the blue crab shows that there might be a limit to the volume of cytoplasm, or fiber perimeter that can be controlled by a myonucleus. During maturational growth of the blue crab, the number of intermyofibrillar myonuclei increase in the anaerobic fibers in addition to an increase in subsarcolemmal nuclei, while in the aerobic fibers they stay at the periphery of the metabolic subdivisions, thereby maintaining the nuclear domain size [61]

Another adaptation could be to increase the rate of diffusion of RNA, which would allow for a lower nuclear density, by increasing the RNA diffusion gradient. An increased RNA gradient can be realized by a higher rate of transcription, which in turn might be achieved by a larger nuclear DNA content. In line with this it has been shown in fish that during maturational muscle growth the nuclear domain size increases, as does the nuclear content per myonucleus [67]. The larger myonuclei in the $100 \%$ hypertrophied muscles of satellite cell depleted mice [16] might be a reflection of an increased transcriptional capacity of the nucleus. It might thus be that we have to consider again the old concept of a constant nuclear size : cytoplasmic volume ratio or nuclear size : fiber perimeter ratio.

\section{Attenuated hypertrophy at old age}

It has been shown in both human [68-70] and animal muscles [66,71-75] that the hypertrophic response is attenuated at old age. Given the above considerations one might wonder which of the discussed limiting factor(s) may become even more limiting at old age, but this has hitherto not systematically been investigated. In most cases attention is given to molecular pathways and changes in the systemic environment of the muscle during ageing [76].

There is quite some evidence that molecular pathways involved in hypertrophy are indeed altered at old age. For instance, during hypertrophy the already phosphorylated 5'-AMP-activated protein kinase (AMPK) is even further phosphorylated and this hyperphosphorylation may impair protein synthesis and hence contribute to the attenuated hypertrophy at old age [75]. Also the upregulation of C-myc after initiation of stretch overload is attenuated in anterior latissimus dorsi muscle of old quail [77] and the elevated expression of inhibitor of differentiation proteins and apoptosis in old rat muscle may underlie the blunting of the increase in myogenic regulatory factors during hypertrophy [71]. These changes, however, are most likely not attributable to a decreased mechanosensitivity of the muscle. In isolated repeatedly passively stretched extensor digitorum longus muscles the phosphorylation of the mechanosensitive stress-activated protein kinase (p38), ribosomal S6 kinase $\left(\mathrm{p} 70^{\mathrm{S} 6 \mathrm{~K}}\right)$ and the $\mathrm{p} 54$ jun N-terminal kinase (JNK2) were the same for 2-3 and 26-27-monthold mice [78]. The phosphorylation of these proteins was independent of release of growth factors, as relaxed muscle co-incubated in close proximity of passively stretched muscles showed no increased phosphorylation of these proteins [78]. This fits the notion that the old muscles transplanted in young recover as well from damage as young muscles transplanted in young animals [79] and that agerelated decline in muscle recovery is more dependent on changes in the systemic environment [80] than the intrinsic plasticity of the muscle. However, recovery from muscle damage and muscle hypertrophy may differ as hypertrophy can develop without the recruitment of satellite cells, while for recovery from muscle damage satellite cell recruitment is obligatory [16].

It is thus possible that the altered systemic environment may contribute to the decreased hypertrophic response at old age. But what about the factors that were discussed in the previous sections? The 'strength' of the bone [81] and tendon [41] decrease with age and this would limit the peak forces that these structures can cope with and at least in theory diminish the maximal attainable hypertrophy at old age. The nuclear domain size [64] and capillary supply do, however, not seem to change much with age [82] and maybe there is another reason for the attenuated muscle hypertrophy at old age.

Here I suggest a possible explanation. During ageing there is a progressive loss of muscle mass beyond the age of about 45 years [8385], which is also reflected by a progressive loss of muscle power [86]. Even in elite master weight lifters a decrease in muscle power occurs, that is proportionally similar, but in absolute terms larger than in nonweightlifters despite maintaining exceptionally high training levels (Figure 2) [87]. Such a phenomenon could be explained by a progressive loss of fibers during ageing. In fact a major part of the muscle wasting is attributable to a loss of muscle fibers as a consequence of the ongoing denervation-reinnervation process [88-90]. If the remaining fibers do maintain their ability to develop hypertrophy to the same extent at young and old age, or in other words the factors that limit fiber (not muscle) hypertrophy stay the same, then at every age also the percentage hypertrophy in response to an identical training program at a given proportion of 1-repetition maximum would be the same (see Figure 2 upward arrows). While the proportional increase in muscle mass in this case stays the same, it can readily be seen in Figure 2 that in absolute terms the hypertrophy becomes smaller with increasing age, a situation similar to that observed in the master weight lifters [87]. It is thus suggested that the attenuated hypertrophy is largely attributable to a decrease in fiber number where each innervated and healthy fiber 
in an old muscle can develop just as much hypertrophy as a fiber in a young muscle. This is, of course speculation, but it would be interesting if such a pattern can indeed be observed in hypertrophied control and old muscles.

Nevertheless, even if the above suggestion is true, also in relative terms the degree of hypertrophy can be attenuated, at least in very old rats [71-73]. To understand this I wish to draw attention again to Figure 2, where it is illustrated that there is a linear decrease in a functional parameter, e.g. muscle mass, at $1 \%$ per year of the value at the age of 30 years. If one, however, expresses the yearly decrement as a percentage of the value in the previous year one readily sees that the rate of deterioration increases exponentially with age (Figure 3). In line with this it has regularly been observed that the age-related rate of decline in longitudinal studies indeed often exceeds that observed in cross-sectional studies [91-93]. This acceleration in the rate of decline could be a reflection of the inability of repair systems to cope with ongoing damage at old age. Any stimulus, like a hypertrophic stimulus to the muscle, would then over-burden the already challenged anabolic system and cause further damage rather than an increase muscle mass. In muscle this would be reflected by a reduction in specific tension, as has indeed been observed in overloaded old rat muscles [73].

\section{Concluding remarks}

There are several factors that in theory could limit the degree of attainable hypertrophy. The maximal degree of hypertrophy seems to be rarely, if ever, reached in response to resistance exercise in untrained people. Only in exceptional cases, such as in bodybuilders, the limits of hypertrophy may be reached, though in avian, rodent and cat models even larger hypertrophy is often observed. It therefore remains to be seen what the limiting factor of hypertrophy really is. It is tempting to speculate that it is the excessive increase in pennation angle that can even result in loss of muscle strength when exceeding $45^{\circ}$, or the size of the joints that is more or less set at puberty. Also metabolism and

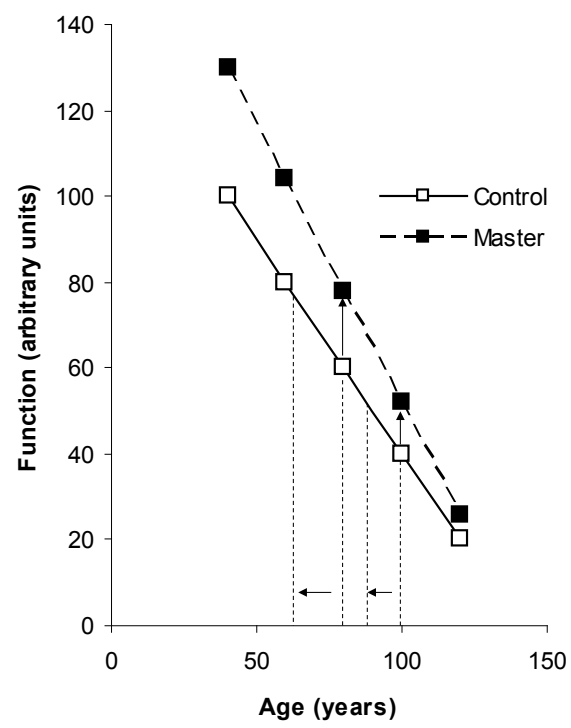

Figure 2: Conceptual presentation of the impact of ageing and training on a physiological parameter (e.g. muscle mass). First notice that there is an agerelated linear decline in functional capacity, here suggested to start at the age of 30 years. It is assumed that the maximal attainable benefit of training at any age is $30 \%$, which results in a 'rejuvenating effect' (indicated by the horizontal arrows) of the functional parameter. It can be seen that 1 . in relative terms the response does not change, while 2. absolute increment and 3 . the maximal attainable 'rejuvenation' with training decreases with age.

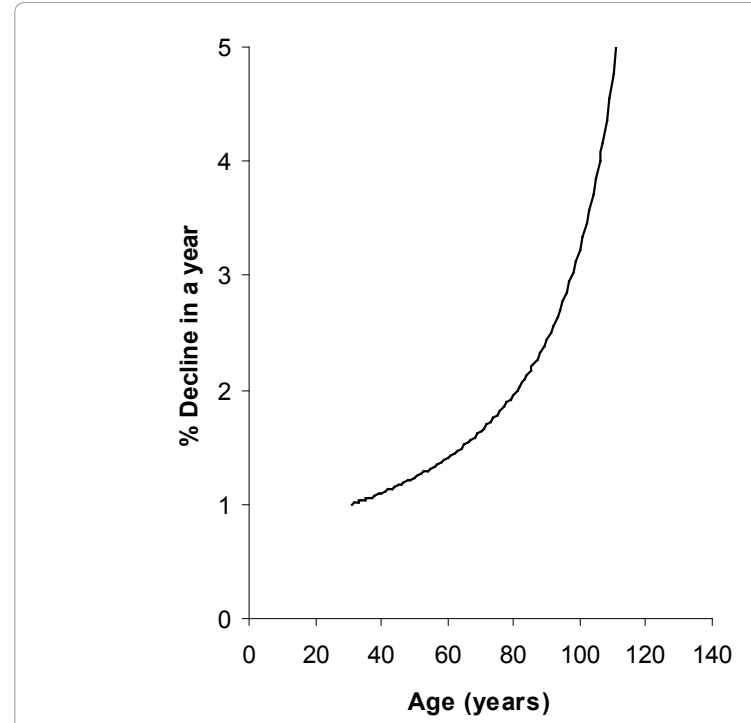

Figure 3: Figure 2 shows a linear age-related decrease in a functional parameter. Compared to the initial functional capacity (here at 30 years) there is a consistent $1 \%$ decline of that functional capacity every year. However, the decline in functional capacity in any given year as a \% of that functional capacity in the previous year shows an exponential rise in the rate of decline during ageing, as illustrated here. This can be interpreted as an increasing rate of 'damage' development during ageing.

diffusion constraints may put an upper limit on hypertrophy where an inverse relationship exists between aerobic capacity of a fiber and the size of a fiber. It is suggested that at least part of the attenuated hypertrophic response at old age is due to loss of fibers during ageing. A better understanding of what factors do in fact limit hypertrophy may help to prevent the athlete and the elderly to 'over-train' their muscles which not only will not be of any additional benefit, but may even result in damage and overtraining symptoms.

\section{Acknowledgements}

The author reports no conflict of interest in this work.

\section{References}

1. Degens H, Erskine RM, Morse $\mathrm{Cl}$ (2009) Disproportionate changes in skeleta muscle strength and size with resistance training and ageing. J Musculoskelet Neuronal Interact 9: 123-129.

2. Erskine RM, Jones DA, Williams AG, Stewart CE, Degens H (2010) Resistance training increases in vivo quadriceps femoris muscle specific tension in young men. Acta Physiol (Oxf) 199: 83-89.

3. Seynnes OR, de Boer M, Narici MV (2007) Early skeletal muscle hypertrophy and architectural changes in response to high-intensity resistance training. $J$ Appl Physiol 102: 368-373

4. Roman WJ, Fleckenstein J, Stray-Gundersen J, Alway SE, Peshock R, et al. (1993) Adaptations in the elbow flexors of elderly males after heavy- resistance training. J Appl Physiol 74: 750-754

5. Jones DA, Rutherford OM, Parker DF (1989) Physiological changes in skeleta muscle as a result of strength training. Q J Exp Physiol 74: 233-256.

6. Folland JP, Williams AG (2007) The adaptations to strength training morphological and neurological contributions to increased strength. Sports medicine 37: 145-168.

7. McCall GE, Byrnes WC, Dickinson A, Pattany PM, Fleck SJ (1996) Muscle fibe hypertrophy, hyperplasia, and capillary density in college men after resistance training. J Appl Physiol 81: 2004-2012.

8. Hather BM, Tesch PA, Buchanan P, Dudley GA (1991) Influence of eccentric actions on skeletal muscle adaptations to resistance training. Acta Physio Scand 143: 177-185. 
9. MacDougall JD, Sale DG, Alway SE, Sutton JR (1984) Muscle fiber number in biceps brachii in bodybuilders and control subjects. J Appl Physiol 57: 13991403.

10. Larsson L, Tesch PA (1986) Motor unit fibre density in extremely hypertrophied skeletal muscles in man. Electrophysiological signs of muscle fibre hyperplasia. Eur J Appl Physiol Occup Physiol 55: 130-136

11. D'Antona G, Lanfranconi F, Pellegrino MA, Brocca L, Adami R, et al. (2006) Skeletal muscle hypertrophy and structure and function of skeletal muscle fibres in male body builders. The J Physiol 570: 611-627.

12. Armstrong RB, lanuzzo CD, Laughlin MH (1986) Blood flow and glycogen use in hypertrophied rat muscles during exercise. J Appl Physiol 61: 683-687.

13. Chalmers GR, Roy RR, Edgerton VR (1992) Variation and limitations in fiber enzymatic and size responses in hypertrophied muscle. J Appl Physiol 73: 631 641.

14. lanuzzo CD, Chen V (1979) Metabolic character of hypertrophied rat muscle. J Appl Physiol 46: 738-742

15. Kandarian SC, Peters DG, Taylor JA, Williams JH (1994) Skeletal muscle overload upregulates the sarcoplasmic reticulum slow calcium pump gene. Am J Physiol 266: C1190-1197.

16. McCarthy JJ, Mula J, Miyazaki M, Erfani R, Garrison K, et al. (2011) Effective fiber hypertrophy in satellite cell-depleted skeletal muscle. Development 138 : 3657-3666.

17. Roy RR, Meadows ID, Baldwin KM, Edgerton VR (1982) Functional significance of compensatory overloaded rat fast muscle. J Appl Physiol 52: 473-478.

18. Bodine SC, Stitt TN, Gonzalez M, Kline WO, Stover GL, et al. (2001) Akt/mTOR pathway is a crucial regulator of skeletal muscle hypertrophy and can prevent muscle atrophy in vivo. Nat Cell Biol 3: 1014-1019.

19. Gollnick PD, Timson BF, Moore RL, Riedy M (1981) Muscular enlargement and number of fibers in skeletal muscles of rats. J Appl Physiol 50: 936-943.

20. Alway SE, Gonyea WJ, Davis ME (1990) Muscle fiber formation and fiber hypertrophy during the onset of stretch-overload. Am J Physiol 259: C92-102.

21. Erskine RM, Jones DA, Maffulli N, Williams AG, Stewart CE, et al. (2011) What causes in vivo muscle specific tension to increase following resistance training? Exp physiol 96: 145-155.

22. Degens H, Veerkamp JH, van Moerkerk HT, Turek Z, Hoofd LJ, et al. (1993) Metabolic capacity, fibre type area and capillarization of rat plantaris muscle. Effects of age, overload and training and relationship with fatigue resistance. Int J Biochem 25: 1141-1148.

23. Tesch PA Thorsson A Colliander EB (1990) Effects of eccentric and concentric resistance training on skeletal muscle substrates, enzyme activities and capillary supply. Acta Physiol Scand 140: 575-580.

24. Baldwin KM, Martinez OM, Cheadle WG (1976) Enzymatic changes in hypertrophied fast-twitch skeletal muscle. Pflugers Arch 364: 229-234.

25. Baldwin KM, Valdez V, Herrick RE, Maclntosh AM, Roy RR (1982) Biochemical properties of overloaded fast-twitch skeletal muscle. J Appl Physiol 52: 467 472.

26. Baldwin KM, Valdez V, Schrader LF, Herrick RE (1981) Effect of functiona overload on substrate oxidation capacity of skeletal muscle. J Appl Physiol 50: 1272-1276

27. Egginton S, Hudlicka O, Brown MD, Walter H, Weiss JB, et al. (1998) Capillary growth in relation to blood flow and performance in overloaded rat skeletal muscle. J Appl Physiol 85: 2025-2032.

28. Degens H, Turek Z, Hoofd LJ, Van't Hof MA, Binkhorst RA (1992) The relationship between capillarisation and fibre types during compensatory hypertrophy of the plantaris muscle in the rat. J Anat 180: 455-463.

29. Plyley MJ, Olmstead BJ, Noble EG (1998) Time course of changes in capillarization in hypertrophied rat plantaris muscle. J Appl Physiol 84: 902-907.

30. Narici MV, Roi GS, Landoni L, Minetti AE, Cerretelli P (1989) Changes in force, cross-sectional area and neural activation during strength training and detraining of the human quadriceps. Eur J Appl Physiol Occup Physiol 59: 310319.

31. Pansarasa O, Rinaldi C, Parente V, Miotti D, Capodaglio P, et al. (2009) Resistance training of long duration modulates force and unloaded shortening velocity of single muscle fibres of young women. J Electromyogr Kinesiol 19 e290-300.
32. Trappe S, Godard M, Gallagher P, Carroll C, Rowden G, et al. (2001) Resistance training improves single muscle fiber contractile function in older women. Am J Physiol Cell Physiol 281: C398-406.

33. Huijing PA (1999) Muscle as a collagen fiber reinforced composite: a review of force transmission in muscle and whole limb. J Biomech 32: 329-345.

34. Patel TJ, Lieber RL (1997) Force transmission in skeletal muscle: from actomyosin to external tendons. Exerc Sport Sci Rev 25: 321-363.

35. Fluck M, Carson JA, Gordon SE, Ziemiecki A, Booth FW (1999) Focal adhesion proteins FAK and paxillin increase in hypertrophied skeletal muscle. Am J Physiol 277: C152-162.

36. Degens H, Hoofd L, Binkhorst RA (1995) Specific force of the rat plantaris muscle changes with age, but not with overload. Mech Ageing Dev 78: 215 219

37. Binkhorst RA, 't Hof MA van (1973) Force-velocity relationship and contraction time of the rat fast plantaris muscle due to compensatory hypertrophy. Pflugers Arch 342: 145-158.

38. Alway SE, Grumbt WH, Stray-Gundersen J, Gonyea WJ (1992) Effects of resistance training on elbow flexors of highly competitive bodybuilders. J App Physiol 72: 1512-1521

39. Kawakami Y, Abe T, Fukunaga T (1993) Muscle-fiber pennation angles are greater in hypertrophied than in normal muscles. J Appl Physiol 74: 2740-2744.

40. Reeves ND (2006) Adaptation of the tendon to mechanical usage. $J$ Musculoskelet Neuronal Interact 6: 174-180.

41. Maganaris CN, Narici MV, Reeves ND (2004) In vivo human tendon mechanica properties: effect of resistance training in old age. J Musculoskelet Neuronal Interact 4: 204-208.

42. Seynnes OR, Erskine RM, Maganaris CN, Longo S, Simoneau EM, et al (2009) Training-induced changes in structural and mechanical properties of the patellar tendon are related to muscle hypertrophy but not to strength gains. $J$ Appl Physiol 107: 523-530.

43. Zumwalt A (2006) The effect of endurance exercise on the morphology of muscle attachment sites. J Exp Biol 209: 444-454.

44. Longo UG, Rittweger J, Garau G, Radonic B, Gutwasser C, et al. (2009) No influence of age, gender, weight, height, and impact profile in achilles tendinopathy in masters track and field athletes. Am J Sports Med 37: 14001405

45. Benjamin M, Toumi H, Ralphs JR, Bydder G, Best TM, et al. (2006) Where tendons and ligaments meet bone: attachment sites ('entheses') in relation to exercise and/or mechanical load. J Anat 208: 471-90.

46. Rittweger J (2008) Ten years muscle-bone hypothesis: what have we learned so far?--almost a festschrift. J Musculoskelet Neuronal Interact 8: 174-178.

47. Gregory JE, Brockett CL, Morgan DL, Whitehead NP, Proske U (2002) Effect of eccentric muscle contractions on Golgi tendon organ responses to passive and active tension in the cat. J Physiol 538: 209-218.

48. van Wessel T, de Haan A, van der Laarse WJ, Jaspers RT (2010) The muscle fiber type-fiber size paradox: hypertrophy or oxidative metabolism? Eur J App Physiol 110: 665-694.

49. Van der Laarse WJ, Des Tombe AL, Lee-De Groot MBE, Diegenbach PC (1998) Size principle of striated muscle cells. Neth J Zool 48: 213-223.

50. Jimenez AG, Dasika SK, Locke BR, Kinsey ST (2011) An evaluation of muscle maintenance costs during fiber hypertrophy in the lobster Homarus americanus: are larger muscle fibers cheaper to maintain? J Exp Biol 214: 3688-3697.

51. Johnston IA, Abercromby M, Andersen O (2006) Muscle fibre number varies with haemoglobin phenotype in Atlantic cod as predicted by the optimal fibre number hypothesis. Biol Lett 2: 590-592.

52. Green H, Goreham C, Ouyang J, Ball-Burnett M, Ranney D (1999) Regulation of fiber size, oxidative potential, and capillarization in human muscle by resistance exercise. Am J Physiol 276: R591-596.

53. Kano Y, Shimegi S, Masuda K, Ohmori H, Katsuta S (1997) Morphologica adaptation of capillary network in compensatory hypertrophied rat plantaris muscle. Eur J Appl Physiol Occup Physiol 75: 97-101.

54. Zhou AL, Egginton S, Brown MD, Hudlicka O (1998) Capillary growth in overloaded, hypertrophic adult rat skeletal muscle: an ultrastructural study. Anat Rec 252: 49-63. 
Citation: Degens H (2012) Determinants of Skeletal Muscle Hypertrophy and the Attenuated Hypertrophic Response at Old Age. J Sport Medic Doping Studie S1:003. doi:10.4172/2161-0673.S1-003

Page 8 of 8

55. Narici MV, Kayser B (1995) Hypertrophic response of human skeletal muscle to strength training in hypoxia and normoxia. Eur J Appl Physiol Occup Physio 70: $213-219$

56. Chaillou T, Koulmann N, Simler N, Meunier A, Serrurier B, et al. (2011) Hypoxia transiently affects skeletal muscle hypertrophy in a functional overload model. Am J Physiol Regul Integr Comp Physiol.

57. Johnston IA (1982) Quantitative analyses of ultrastructure and vascularization of the slow muscle fibres of the anchovy. Tissue cell 14: 319-328.

58. Hoofd L, Egginton S (1997) The possible role of intracellular lipid in determining oxygen delivery to fish skeletal muscle. Respir Physiol 107: 191-202.

59. de Koning J, Hoofd LJ, Kreuzer F (1981) Oxygen transport and the function of myoglobin. Theoretical model and experiments in chicken gizzard smooth muscle. Pflugers Arch 389: 211-217.

60. Masuda K, Kano Y, Katsuta S (1997) Adaptation of myoglobin in compensatory hypertrophied rat muscle. Acta Physiol Scand 160: 327-331.

61. Hardy KM, Dillaman RM, Locke BR, Kinsey ST (2009) A skeletal muscle model of extreme hypertrophic growth reveals the influence of diffusion on cellular design. Am J Physiol Regul Integr Comp Physiol 296: R1855-1867.

62. Kinsey ST, Hardy KM, Locke BR (2007) The long and winding road: influences of intracellular metabolite diffusion on cellular organization and metabolism in skeletal muscle. J Exp Biol 210: 3505-3512.

63. Russell B, Dix DJ (1992) Mechanisms for intracellular distribution of mRNA: in situ hybridization studies in muscle. Am J Physiol 262: C1-8.

64. Van der Meer SF, Jaspers RT, Degens $H$ (2011) Is the myonuclear domain size fixed? J Musculoskelet Neuronal Interact 11: 286-297.

65. van der Meer SF, Jaspers RT, Jones DA, Degens H (2011) The time course of myonuclear accretion during hypertrophy in young adult and older rat plantaris muscle. Ann Anat 193: 56-63.

66. Lee J, Alway SE (1996) Adaptations of myonuclei to hypertrophy in patagialis muscle fibers from aged quail. Mech Ageing Dev 88: 185-197.

67. Jimenez AG, Kinsey ST (2011) Nuclear DNA content variation associated with muscle fiber hypertrophic growth in fishes. J Comp Physiol B.

68. Raue U, Slivka D, Minchev K, Trappe S (2009) Improvements in whole muscle and myocellular function are limited with high-intensity resistance training in octogenarian women. J Appl Physiol 106: 1611-1617.

69. Welle S, Totterman S, Thornton C (1996) Effect of age on muscle hypertrophy induced by resistance training. J Gerontol A Biol Sci Med Sci 51: M270-275.

70. Petrella JK, Kim JS, Cross JM, Kosek DJ, Bamman MM (2006) Efficacy of myonuclear addition may explain differential myofiber growth among resistance-trained young and older men and women. Am J Physiol Endocrinol Metab 291: E937-946.

71. Alway SE, Degens H, Krishnamurthy G, Smith CA (2002) Potential role for Id myogenic repressors in apoptosis and attenuation of hypertrophy in muscles of aged rats. Am J Physiol Cell Physiol 283: C66-76.

72. Blough ER, Linderman JK (2000) Lack of skeletal muscle hypertrophy in very aged male Fischer 344 x Brown Norway rats. J Appl Physiol 88: 1265-1270.

73. Degens H, Alway SE (2003) Skeletal muscle function and hypertrophy are diminished in old age. Muscle Nerve 27: 339-347.

74. Mackova E, Hnik P (1972) Time course of compensatory hypertrophy of slow and fast rat muscles in relation to age. Physiol Bohemoslov 21: 9-17.

75. Thomson DM, Gordon SE (2005) Diminished overload-induced hypertrophy in aged fast-twitch skeletal muscle is associated with AMPK hyperphosphorylation. J Appl Physiol 98: 557-564

76. Degens H (2010) The role of systemic inflammation in age-related muscle weakness and wasting. Scand J Med Sci Sports 20: 28-38.

77. Alway SE (1997) Overload-induced C-Myc oncoprotein is reduced in aged skeletal muscle. The journals of gerontology. J Gerontol A Biol Sci Med Sci 52: B203-211.

78. Hornberger TA, Mateja RD, Chin ER, Andrews JL, Esser KA (2005) Aging does not alter the mechanosensitivity of the p38, p70S6k, and JNK2 signaling pathways in skeletal muscle. J Appl Physiol 98: 1562-1566.

79. Carlson BM, Faulkner JA (1989) Muscle transplantation between young and old rats: age of host determines recovery. Am J Physiol 256: C1262-1266.
80. Conboy IM, Conboy MJ, Wagers AJ, Girma ER, Weissman IL, et al. (2005) Rejuvenation of aged progenitor cells by exposure to a young systemic environment. Nature 433: 760-764.

81. Wust RC, Winwood K, Wilks DC, Morse Cl, Degens H, et al. (2010) Effects of smoking on tibial and radial bone mass and strength may diminish with age. $J$ Clin Endocrinol Metab 95: 2763-2771.

82. Degens H (1998) Age-related changes in the microcirculation of skeletal muscle. Adv Exp Med Biol 454: 343-348.

83. Doherty TJ (2003) Invited review: Aging and sarcopenia. J Appl Physiol 95: 1717-1727.

84. Janssen I, Heymsfield SB, Wang ZM, Ross R (2000) Skeletal muscle mass and distribution in 468 men and women aged 18-88 yr. J Appl Physiol 89: 81-88.

85. Lexell J, Taylor CC, Sjostrom M (1988) What is the cause of the ageing atrophy? Total number, size and proportion of different fiber types studied in whole vastus lateralis muscle from 15- to 83 -year-old men. J Neurol Sci 84 275-294.

86. Runge M, Rittweger J, Russo CR, Schiessl H, Felsenberg D (2004) Is muscle power output a key factor in the age-related decline in physical performance? A comparison of muscle cross section, chair-rising test and jumping power. Clin Physiol Funct Imaging 24: 335-340.

87. Pearson SJ, Young A, Macaluso A, Devito G, Nimmo MA, et al. (2002) Muscle function in elite master weightlifters. Med Sci Sports Exerc 34: 1199-1206.

88. Faulkner JA, Larkin LM, Claflin DR, Brooks SV (2007) Age-related changes in the structure and function of skeletal muscles. Clin Exp Pharmacol Physiol 34 1091-1096.

89. Larsson L, Ansved T (1995) Effects of ageing on the motor unit. Prog Neurobio 45: $397-458$

90. Lexell J (1997) Evidence for nervous system degeneration with advancing age. J Nutr 127: 1011S-1013S.

91. Frontera WR, Hughes VA, Fielding RA, Fiatarone MA, Evans WJ, et al. (2000) Aging of skeletal muscle: a 12-yr longitudinal study. J Appl Physiol 88: 1321 1326.

92. Frontera WR, Reid KF, Phillips EM, Krivickas LS, Hughes VA, et al. (2008) Muscle fiber size and function in elderly humans: a longitudinal study. J App Physiol 105: 637-642.

93. Tanaka H, Seals DR (2008) Endurance exercise performance in Masters athletes: age-associated changes and underlying physiological mechanisms. J Physiol 586: 55-63.

94. Frischknecht R, Vrbova G (1991) Adaptation of rat extensor digitorum longus to overload and increased activity. Pflugers Arch 419: 319-326. 